\title{
Development and fabrication of vehicle body paints mixing machine
}

\author{
Frederic Musabyimana ${ }^{1}$, Pacifique Turabimana ${ }^{2 *}$
}

\author{
${ }^{1}$ Department of Mechanical Engineering, Automobile Technology, IPRC Kigali/Rwanda Polytechnic, Kigali Rwanda \\ ${ }^{2}$ Department of Mechanical Engineering, Automobile Technology, IPRC Gishari/Rwanda Polytechnic, Rwamagana Rwanda
}

\section{ABSTRACT}

The exterior surface attractive appearance of every designed and the fabricated machine includes the vehicles is determined by the type of paint color it has to the one who takes its looks. The well-painted machine is added its value to the customers from its physical outer appearance. High attractive paint color from paint mixing activities plays an important role in the production mechanism of any attractive exterior surfaces have done by the painter industries and auto body repair companies. In some developing countries with a low percentage of industries including Rwanda, finding a standardized auto-body paint mixing machine is very expensive. Then, auto-body repair and painters in different vehicle repair industries and garages try to mix paints by using their hands without other assistance which is known as manual auto-paint mixing operation. However, this manual mixing method has several disadvantages like unattractive paint colors, low painting quality outputs, unresisting paint to solar, and rain which reduce the product's value. During the mixing operation, their hands' skin being unhealthy because of the chemicals from the paints and respiration system affected by paint smell. This method takes more time during mixing but resulted in a non-uniformity of mixed paint. Therefore, this research aim is to design and implement a paint mixing machine with accurate paint color at an affordable cost. The machine is fabricated using the materials which are available on local markets. This machine will offer more benefits to the vehicle repair companies, vehicle sellers, and dealers such as time reduction taken during vehicle body painting, more customers, the confidentiality of taking the used vehicles to the markets.

Keywords: electric engine, modelling of an electric vehicle, simulation, Matlab/Simulink, NEDC, electric vehicle, electrical bus

\begin{tabular}{cll}
\hline History & Author Contacts & http://dx.doi.org/10.29228/eng.pers.52083 \\
Received: 12.06 .2021 & *Corresponding Author \\
Accepted: 30.08 .2021 & e-mail addresses : pacifique.turabimana@ aait.edu.et, fredmusa2018@gmail.com \\
& Orcid numbers : 0000-0003-2422-9056,0000-0001-9164-6648 \\
\hline
\end{tabular}

\section{Introduction}

The Paint mixers demand a design that balances time and uniformity of different paint colors during painting operation to the good body color appearance. The automobile researchers are always thinking about the vehicle body surface as one of the parameters to identify a vehicle to another. It is also protecting the vehicles against fading from the sun rays UV and facilitate vehicle body repair and maintenance in a simple way [1]. The vehicle body repaired from different garages are distinguished according to their paint colors' quality which are generated to the technicity of body painting service and the paints coat control has used during painting operation [2].

The vehicle repair industries and researchers are continually trying different technologies deal with vehicle body paint uniformity and Yong-Hee Han with his colleagues in 2003 come up with the research of developing a paint coating technology where a unique polymer layer with iron oxide particles is applied to the vehicle body during vehicle body painting. The vehicle color is defined by the vehicle type and its uses and interpreted by the human eyes. And their research identifies that painting a vehicle with different paints color to the original one during maintenance is more costly. Vehicle body paint mechanism and paint mixing colors are more expensive [3]. The vehicle coatings and the methods used to coat vehicle surfaces are identified by applied technologies. The purpose is to get the vehicle's body appearance exceeding the customers' expectations. The mixing operation should meet the high paint mixing efficiency and fulfill the environmental regulations. From these parameters, different vehicle body paint mixing methods have been developed by different researchers as the main key to make a good surface appearance [4].

The first method of paint mixing operation was the pure manual. The paints with different colors were mixed in one container 
to have one species' paint used to the vehicle body like the building painting operation. It takes time to have an attractive paint color for the customers. And getting the color quality standard is also not possible with this method. Hence this manual method, plastic or a wooden stick material is used to mix paints in a container by hands during agitation [5] and [6]. The output paint color is not attractive to this mixing method. The mixing of different paint colors to a large quantity manually demands more energy to operate. There is no way of measuring the output efficiency, environmental impact, and coating factor resistance to high temperature during more sun lens and low temperature and snow. The process of mixing is an important operation for auto body coating. This method plays a big role in having a welldefined body coat. The paints to be mixed are bought in liquid or powder and play the same roles to the body surface. However, for automotive paints, the liquid is mostly used.

The automotive industries and the researchers developed the mixing machines as an alternative good solution to the manual mixing method. During this period, the liquid auto-body paint mixing steps have been elaborated and classified into five phases. The phases are reactions, blending homogenization, emulsion preparation, dissolution, and paint extraction. The electrically operated paints mixing machine has developed with highly accurate and good appearance of vehicle paint color [7]. The mixing of paint powders is operated differently from the liquid mixing process. It needs to be done by rigorous shaking and creating turbulence that makes paints uniform of the paint's particles. Hence, the powder paints are mixed using the reversible mixer. It gives partial homogenization for more effective homogeneity during the mixing operation. This process has a cyclic reversal of the machine rotor and creates more effective agitating turbulence [8]. The paints mixing machines are many available on the world market but not all used to the small firm of automobile garages. The below table 1 shows the different types of paint mixing machines classifications.

Table 1. Machine classification with their disadvantages

\begin{tabular}{|l|l|l|l|}
\hline S/N & Machine & Advantage & Disadvantage \\
\hline 1 & $\begin{array}{l}\text { Manual ope } \\
\text { rated machi } \\
\text { ne }\end{array}$ & $\begin{array}{l}\text { Simple to o } \\
\text { perate even } \\
\text { unskilled pe } \\
\text { rson }\end{array}$ & $\begin{array}{l}\text { Less quality of mixe } \\
\text { d paint uniformity }\end{array}$ \\
\hline 2 & $\begin{array}{l}\text { High speed } \\
\text { electrical op } \\
\text { mixared paint } \\
\text { mixer }\end{array}$ & $\begin{array}{l}\text { quang high } \\
\text { short time }\end{array}$ & $\begin{array}{l}\text { Used to high deman } \\
\text { d manufacturing ind } \\
\text { ustries due and not } \\
\text { affordable for small } \\
\text { firm industries becau } \\
\text { se of its cost }\end{array}$ \\
\hline 3 & $\begin{array}{l}\text { Computerise } \\
\text { d automatic } \\
\text { mixing mac } \\
\text { hine }\end{array}$ & $\begin{array}{l}\text { High quality } \\
\text { of mixed } \\
\text { paints }\end{array}$ & $\begin{array}{l}\text { High cost and need } \\
\text { high skilled operator } \\
\text { s }\end{array}$ \\
\hline
\end{tabular}

This research article finds out the paint mixing method to overcome the disadvantages of the previously developed methods. This method is between manual and full- automatic mixing operations. The process of mixing is simple and human healthy.
The developed paint mixing machine is simple to operate, easy for maintenance, and simple for transportation. The uniformity of paint color is easy to be obtained with vehicle body paint color standardized quality. The two methods have been used in this research. The first one is the design of the machine using Solid works software. The second method is an implementation of a physical model. This method starts with a preliminary measurement of machine structure components. The sizes of its parts fulfil the standards of mixer in line with dimensions of a reacting vessel, machine parts marking, metal cutting on sizes, sheet metal rolling and folding, and welding as the machine assembling mechanism during fabrication. The machine is electrically operated with high efficiency of auto-body color paints uniformity to the affordable cost.

\section{Materials and methods}

This fabricated paint mixing machine is semi-automatic machine because of its working principle. It is electrically operated and consists of various parts connected each other in a pre-designed manner and guided in a constrained way to obtain required outputs. This machine is designed in SolidWorks software and simulated in ANSYS software to the actual working environment for the finite element analysis of the machine structure to check its structure materials workability during machine operation. This machine structure frame is made by a strong steel cylindrical sheet metal designed to which is installed an A/C Single-phase Electric Motor with extended center shaft holder of two blades paint mixer designed to splash paint when rotating in the tank. The assembly is fixed on a strong stand made in tube of $20 \times 20 \times 1.6$ by welding. At the bottom of the cylinder, it has a van used to drain out the mixed paint. The detailed machine parts and their dimensions are shown in Table 1.

Table 2. Machine parts and dimensions

\begin{tabular}{|c|c|c|c|}
\hline Part & \multicolumn{3}{|c|}{ Dimensions in mm } \\
\hline \multirow{3}{*}{ Tank } & $\begin{array}{c}\text { Height } \\
(H)\end{array}$ & $\begin{array}{c}\text { Body dimeter } \\
(D)\end{array}$ & $\begin{array}{c}\text { Base dimeter } \\
\left(D_{b}\right)\end{array}$ \\
\cline { 2 - 4 } & 200 & 173 & 213 \\
\hline \multirow{3}{*}{ Motor } & $\begin{array}{c}\text { Shaft Leng } \\
\text { th }(L)\end{array}$ & $\begin{array}{c}\text { Shaft Dimeter } \\
(d)\end{array}$ & $\begin{array}{c}\text { Revolution } \\
(N)\end{array}$ \\
\cline { 2 - 4 } & 320 & 12 & $3000 \mathrm{rpm}$ \\
\hline \multirow{3}{*}{ Mixer } & $\begin{array}{c}\text { Shaft dime } \\
\text { ter }(d)\end{array}$ & $\begin{array}{c}\text { Horizontal bla } \\
\text { de length }(B)\end{array}$ & $\begin{array}{c}\text { Vertical blade } \\
\text { length }(V)\end{array}$ \\
\cline { 2 - 4 } & 12 & 148 & 101 \\
\hline Stand & Height $(h)$ & Length $(l)$ & Width $(w)$ \\
\cline { 2 - 4 } & 300 & 170 & 120 \\
\hline
\end{tabular}

The design of a structural mechanism of the stand is based on the weight of the electrical motor, rotational speed, and vibration. And also, the mechanical properties of the mechanical structures have been taken under consideration. The considered properties are for the steel tubes and sheet metal. Due to steel is the main material used for machine structure. The designing consideration properties are strength, toughness, ductility, durability, weldability, and durability. The values taken was the maximum by minimizing machine maintenance cost [9]. The metal 
joining method used is a permanent joining by welding and temporally joining by bolting method. During assembling, the weldability factor has been considered based on joint cooling time, joint useful life, and workability resistance (corrosion, environmental effects, electrical motor resistance, and the total weight of the machine) from the International Organisation Standardization (ISO) report, ISO standard 2020 [10].

Figure 1. Assembled auto body paints mixing machine

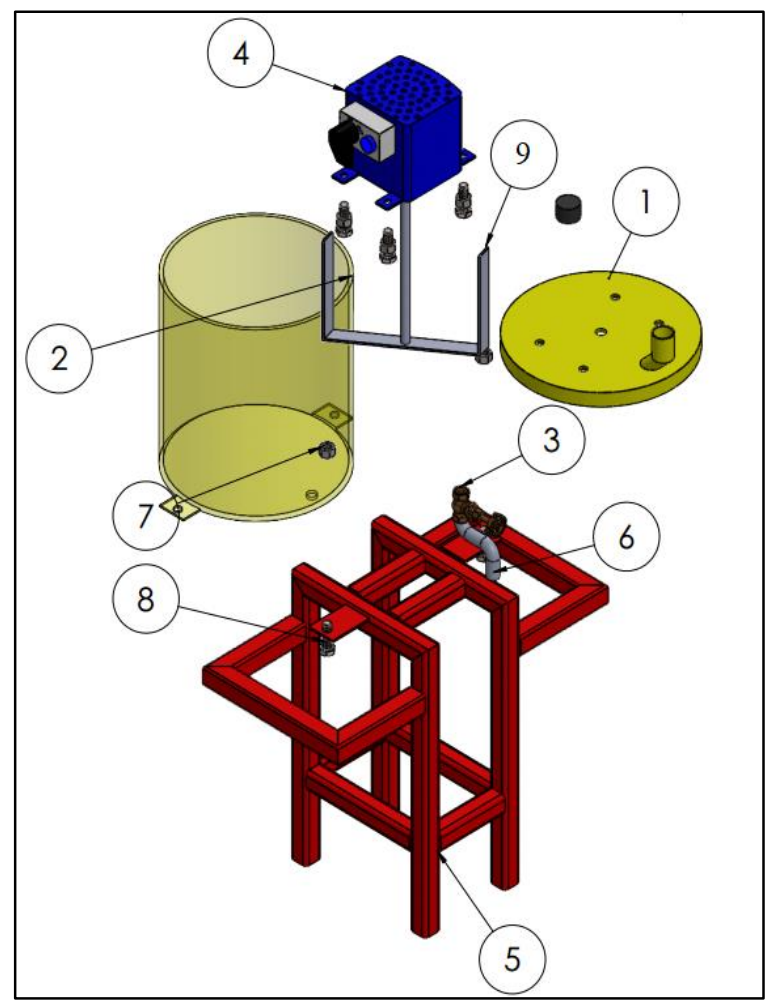

The motor has a blue color indicates that it was inserted from software features to the prescribed dimensions of the machine parts. Figure 1 illustrates the four tubes making a stand are well seated to facilitate good machine stability during operation. Hence all machine parts are available on the market at a low price. The importing mart is only an electrical motor. The way country's industrialization sector is starting to be developed, there is a hope that in a few years electrical motor will be available on the local market. But also, the motor doesn't increase too much the cost of the machine [11]. All joints of the stand are permanent by welding method. The assembling parts are illustrated in Figure 2. The assembling of electrical motor and tank is made by bolting, assembling of tank and stand is made by bolting while the pipes are fixed the tank using plumbing fittings.

The accessibility of machine parts or components is not complicated and makes the good maintainability of the machine. The assembling and disassembling are simple compare to the machines which have many hidden components. The mechanism of operation is designed to help in fault detection and repair which makes this machine to be friendly to operators. The machine dimensions like height from the ground are defined based on the average height of a human being for ease and comfort while operating the machine. The machine is painted to protect it against corrosion, sunlight, heavy rain, and keeping its exterior view [12]. The height of the machine is at the mean level to facilitate easy operability, also enough clearance is provided from the ground for cleaning purposes. This height doesn't affect the operating of the machine. The selection of materials was also based on machine weight. The machine weight is well defined to facilitate its transportation. The more garages in Rwanda work on vehicle body repair are not able to buy the machine but can rent it to make their finishing work to be attractive.

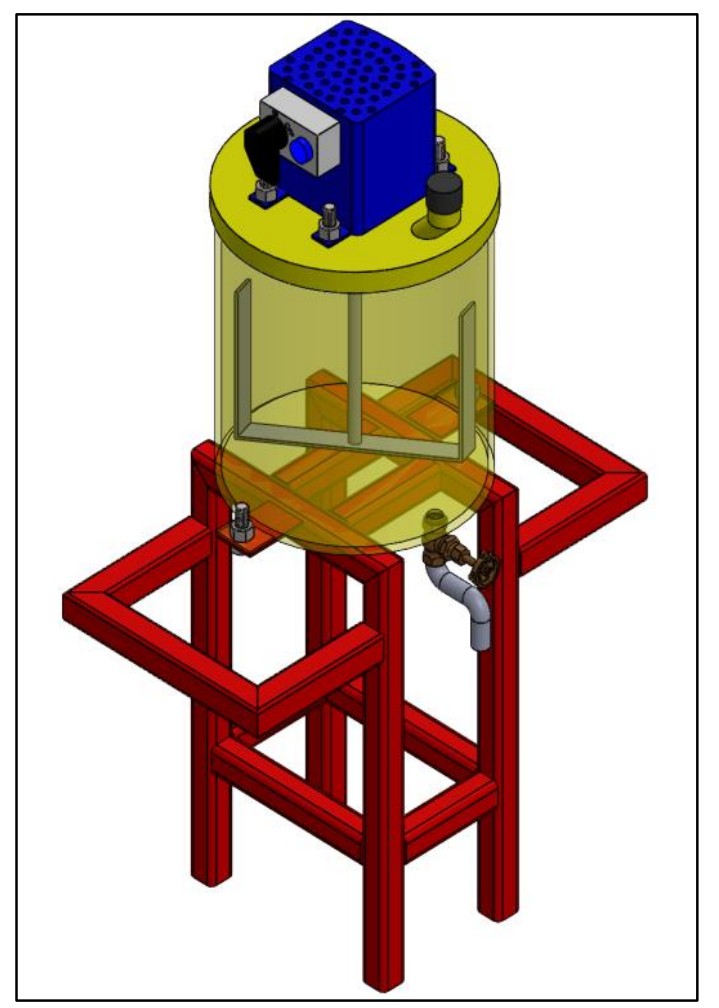

Figure 2. Machine parts drawn in solidworks (1. Cup for tank, 2. Tank, 3. Ball valve, 4. Assembled motor, 5. Stand, 6. Plastic pipe, 7. M8-S nut, 8. Bolt M8 and 9. Mixer blades)

The quantity of paint to be mixed depends the tank inter-nal volume and the revolution per minute of the electrical motor. The motor rotation is one of the parameters have been considered to facilitate the selection of a useful motor. The tank volume is calculated using the below equation to mitigate machine purpose.

$$
V=\left(\frac{\pi D_{b}^{2}}{4} H\right)\left(\frac{\pi\left(D_{b}-D\right)^{2}}{4} H\right)
$$

Where, $\boldsymbol{V}$ is the tank volume, $\boldsymbol{D}$ is the tank body diameter, $\boldsymbol{D}_{\boldsymbol{b}}$ is the tank base dimeter, $\boldsymbol{H}$ is the height of the tank. 


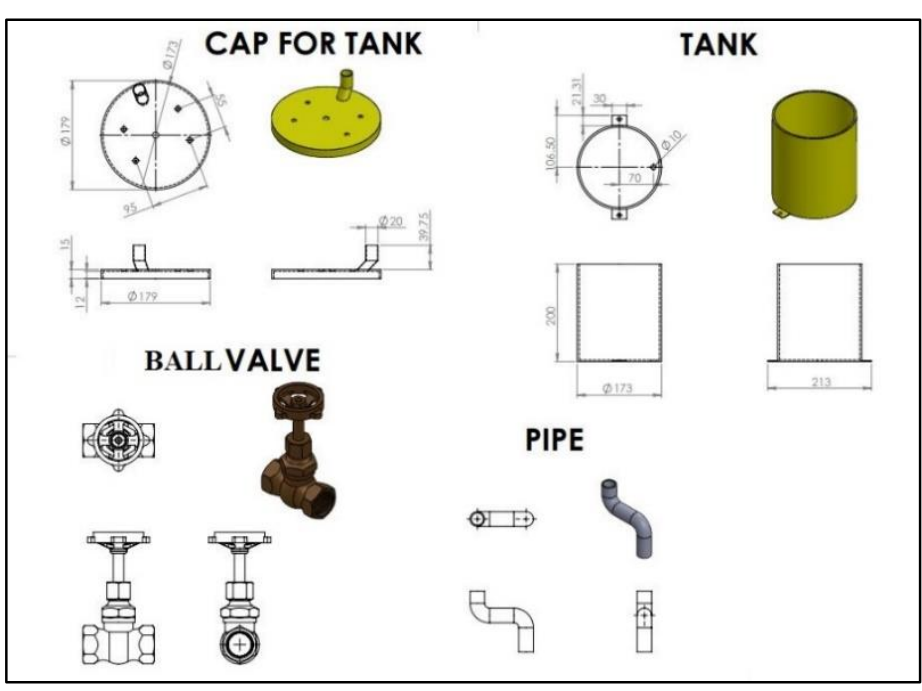

Figure 3: The most parts of the machine required attention checking and their view

\section{Machine operation}

The tank of the machine has a cylindrical shape and doesn't rotate. The rotating part is the shaft of the motor assembled with two tubes. During rotation of the motor shaft, these tubes rotate at the same speed as the shaft in paint and agitate all paint particles to form a similar species and form one color. The motor shaft is taken as the center shaft of the mixer and the assembled tubes are called mixer beaters. Hence the motor used is an alternating current motor type. The circular base of the hopper/ tank is assembled with a valve made by a short plastic pipe. This plastic pipe is used to take out the mixed paints from the tank after the mixing operation. The operation control including the electrical circuit breaker, control button (Switch ON/OFF) of the machine is fixed to the stand. When the machine is in the operation state there is a powerful lamp which is on and if the machine is in off mode the power is off.

The moving part has a predefined degree of freedom to make agitation of the paint mixture to the homogeneity output. The stability and vibration of the rotating part are well managed by the fixed parts (tank and stand). The machine uses an air-cooling system and it requires to be fixed in vent space to facilitate its cooling system. The steps of operating the machine are:

- Check the place to operate the machine is well flat and horizontal,

- Check if the stand is well seated on the ground,

- Check the connection of electricity to the electrical machine and the position of circuit breakers,

- Clean the tank using recommended solvent (Thinner or Petrol) and let it be dried,

- Open all the paint bags being mixed,

- Check all the valves if are well closed,

- Pour the paints in the tank and close the tank cover or cup properly,

- Switch on the machine and let work within 4 minutes switch it off and check the viscosity and color of the output mixture.
- If, it is well done, open full the valve and keep paint in a standardized prepared material

- Clean the tank before 2 minutes of removing the paints if you are not going to use the machine again with the same paint color or type.

- The operator of the machine should always have safety protective equipment.

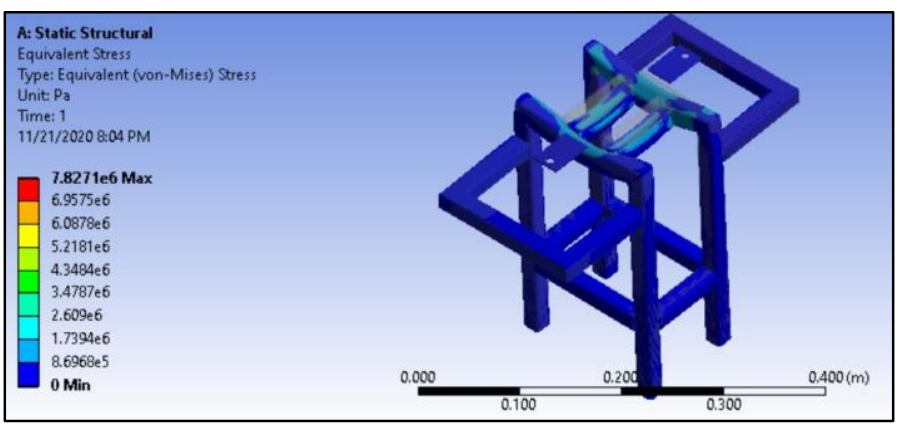

Figure 4. Machine stand Equivalent (von-Mises) stress (pa)

\section{Results and Discussion}

The stand of this machine is designed to support permanent load (the load of machine components) plus the variable load (load of paint in the tank to be mixed). The total load can't exceed $120 \mathrm{~kg}$. The stress concentration is on these two tubes fixing the tank and motor on the stand. However, the operability of the machine does not be affected by this stress. During operation, the stand can't reach the maximum stress. It works near to the minimum as it is shown in Figure 4. The maximum equivalent stress to be supported by the machine is $7.8271 \mathrm{e} 6 \mathrm{~Pa}$. At maximum load and motor speed, the maximum stress of the machine is $8.6968 \mathrm{e} 5 \mathrm{~Pa}$. It can't affect the operation of the machine stand. See Figure 4.

Figure 5 indicates the possible maximum and minimum deformation of the machine. The maximum deformation is $1.8022 \mathrm{e}-6$ $\mathrm{m}$ at point application of the joint between the tank and the stand when the machine operates at maximum speed and load. This means that once the machine operates everyday none stop with maximum loads, two tubes fixing the tank should be replaced once a year. The option of adding the tube support to the verticals makes the machine operates well without reaching its maximum deformation. And instead of replacing the tubes joining the tank to the machine, the supports are replaced once in three years. It is the best option to keep the machine with a low maintenance cost. Figure 6 illustrates the variation of the stand metal deformation with the maximum frequency vibration of the machine. This implies that the deformation increases while the machine is not well seated to the horizontal plane. When vibration increases the deformation increase after $147 \mathrm{~Hz}$. Before $147 \mathrm{~Hz}$ vibration can't affect the machine because the material properties have chosen to work with 180 RPM motor speed. 


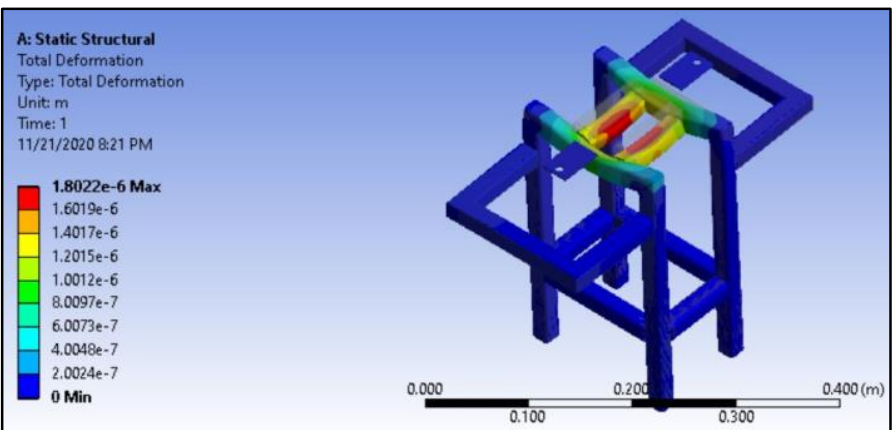

Figure 5. Total deformation of the machine stand

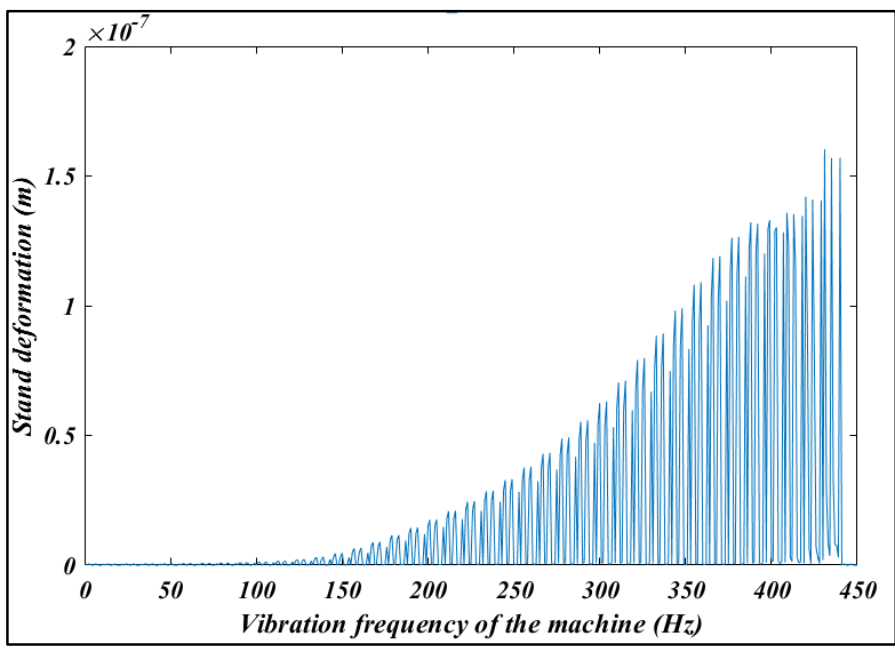

Figure 6 . The stand deformation to vibration frequency of the machine

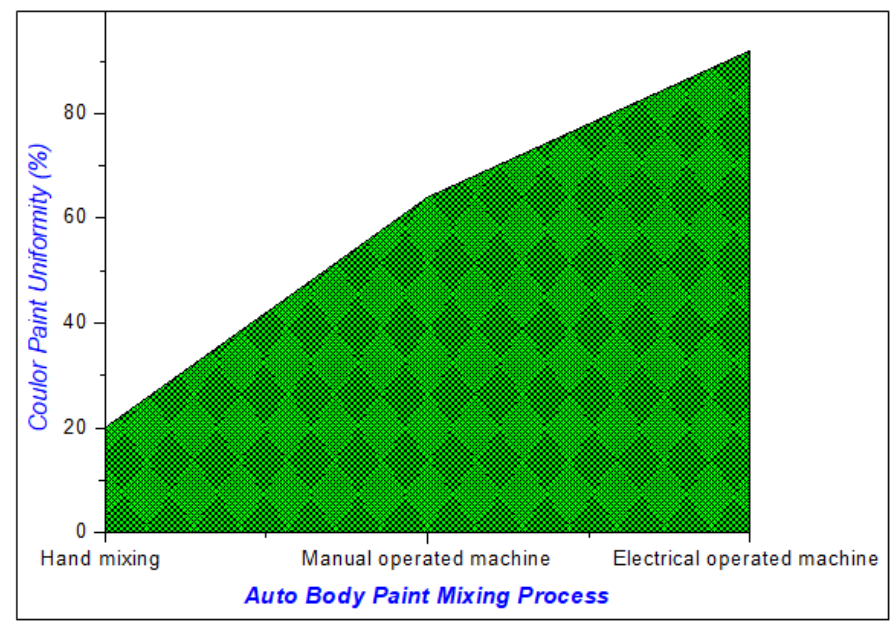

Figure 7. Auto body Painting uniformity

Figure 7 illustrates the operability of available mixing methods in Rwanda with the output's paints color uniformity. The comparative study of the auto-body paint mixing machines available in the Rwanda market shows that this electrically operated machine performs well compare to other mechanical operated machines and hand mixing method. This machine doesn't have $100 \%$ paint uniformity. It reaches $91 \%$ paint mixture uniformity.
The analysis was base to the practices we did in the manufacturing workshop during the all-manufacturing process of this machine. There used the hand mixing method and manually operated mixing machine. We took 8 samples of paint mixture from 4 paint colors to have one uniform paint color used to paint on a monocoque vehicle body. The obtained results show that the quality of color uniformity of the two methods (hand mixing and manual operated) is too low and took more time of mixing process compared to this machine. None goes up to $65 \%$ of color uniformity. This electrically operated machine uses only $1 / 14$ of the total time other methods to get the required attractive color paint uniformity.

\section{Conclusion}

In this research, the study of paint properties has done to meet the designing and fabricate paint mixing machine that is able to mix paints with different colors to the single attractive color of the vehicle body. The machine works above $90 \%$ of color uniformity at high speed and its cost is affordable. The auto body repair will be improved and to use this machine is to save more time and attracting the customers to use the garage. As the need for paint production has a high increasing rate in the country, this then becomes our reason for the fabrication of an electric motor is driven paint mixer. It solves the problems of Rwanda's automotive garages. However, it is a good solution to producing local paint mixing machines that can serve our society. The future works are to improve its mixture uniformity to $100 \%$ and increasing the maximum load capacity to be mixed for one round.

\section{Conflict of Interest Statement}

The authors declare that there is no conflict of interest.

\section{CRediT Author Statement}

Frederic Musabyimana: Supervision, methodology, article editing, Writing original draft and revision; Pacifique Turabimana: Methodology, article editing, Writing original draft and revision.

\section{Acknowledgements}

We would like to acknowledge the Rwanda Polytechnic for the funds provided in carrying out this project through its initiative of supporting research projects by equipping the workshops where we did our prototype models and physical model. We want also to acknowledge the IPRC Kigali workshop instructors for their exceptional collaboration during the implementation of this auto body paint mixing machine.

\section{References}

1. Gerlock, J. L., Kucherov, A. V., \& Smith, C. A. (2001). Determination of active HALS in automotive paint systems II: HALS distribution in weathered clearcoat/basecoat paint systems. Polymer degradation and stability, 73(2), 201-210.

2. Jones, F. N., Nichols, M. E., \& Pappas, S. P. (2017). Organic coatings: science and technology. John Wiley \& Sons. 
3. Han, Y. H., Zhou, C., Bras, B., McGinnis, L., Carmichael, C., \& Newcomb, P. J. (2003). Paint line color change reduction in automobile assembly through simulation. In Winter Simulation Conference (Vol. 2, pp. 1204-1209).

4. Akafuah, N. K., Poozesh, S., Salaimeh, A., Patrick, G., Lawler, K., \& Saito, K. (2016). Evolution of the automotive body coating process-A review. Coatings, 6(2), 24.

5. Richard C.G., (2018) "Development of a Paint Mixing Machine," International Journal of Academic Engineering Research, 2(4), 916.

6. Pfanstiehl, J. (1998). Automotive paint handbook: paint technology for auto enthusiasts \& body shop professionals. Penguin.

7. Lacey J. (2009). Occupational Exposures in Paint Manufacturing and Painting," Petroleum distillate Solvents.

8. Scicolone, J., Mujumdar, A., Sundaresan, S., \& Davé, R. N. (2011). Environmentally benign dry mechanical mixing of nanoparticles using magnetically assisted impaction mixing process. Powder technology, 209(1-3), 138-146.

9. Davison, B., \& Owens, G. W. (Eds.). (2012). Steel designers' manual. John Wiley \& Sons.

10. STANDARD, B. (2002). Welding-Recommendations for welding of metallic materials-. Change, 13981, 30.

11. Omorusi, I. I. (2020). Design and Construction of an Electrically Operated Paint Mixing Machine. Journal of Engineering Research and Reports, 20-29.

12. Castano, C. E., Fahrenholtz, W. G., \& O'Keefe, M. J. (2020). Ceria-based coatings and pigments. Cerium Oxide $\left(\mathrm{CeO}_{2}\right)$ : Synthesis, Properties and Applications, 211-257. 